\title{
Um corpus anotado de construções com verbo-suporte em Português
}

\author{
Amanda Pontes Rassi ${ }^{a}$ \\ Jorge Baptista ${ }^{b}$ \\ Oto Araújo Vale
}

\begin{abstract}
Resumo
As construções com verbo-suporte (CVS) são um tipo de construção nominal, em que o predicador central é o nome, chamado de nome predicativo (Npred), e este é auxiliado por um verbo, chamado verbo-suporte (Vsup). A abordagem utilizada para a descrição e formalização das CVS, neste artigo, é o Léxico-Gramática. Tendo em vista as diferenças sintáticas e semânticas das CVS em relação a outros tipos de construções, o objetivo deste artigo é apresentar a metodologia e os resultados da construção de um corpus anotado com construções de Vsup e de Npred. Foi construída uma lista com 4.668 CVS, considerando-se 45 variantes de Vsup e cerca de 3.200 Npred diferentes. A partir dessa lista de CVS, foram extraídas 121.198 frases do corpus PLN.Br Full, das quais foi anotada e revista manualmente uma amostra com 2.646 frases, que constituem o corpus de referência para o tratamento de CVS em Português. Esse corpus de referência poderá ser utilizado como golden standard para avaliar tarefas automáticas de identificação, extração ou classificação de CVS ou ainda para outras aplicações de Processamento Automático de Língua Natural (PLN).
\end{abstract}

Palavras-chave: verbo-suporte, nome predicativo, Léxico-Gramática, anotação de corpus.

aUniversidade Federal de São Carlos - UFSCar, Universidade do Algarve - Ualg. amandarassi85@hotmail.com bUniversidade do Algarve - Ualg. jbaptis@ualg.pt

‘Universidade Federal de São Carlos - UFSCar, Université Catholique de Louvain - UCL. otovale@ufscar.br 


\section{Introdução}

As construções com verbo-suporte (CVS) são formadas, a rigor, por um verbo que funciona como verbo-suporte (Vsup) e um nome que funciona como nome predicativo (Npred). Uma mesma forma verbal, como por exemplo o verbo dar, pode ser o predicador em construções dativas (e.g. Rui deu um livro à Ana) ou pode funcionar como uma espécie de verbo auxiliar em construções com verbo-suporte (e.g. Rui deu um beijo na Ana). No mesmo sentido, uma forma substantival pode funcionar ora como nome concreto, argumento de um predicado verbal (e.g. Rui guardou a proposta na gaveta) ou pode funcionar como nome predicativo, em um predicado nominal (e.g. Rui fez uma proposta à Ana).

Nas CVS, o elemento predicador central é o Npred, definido como um substantivo abstrato, eventivo, que impõe as restrições de seleção dos argumentos (sujeito e complementos essenciais) da construção. O verbo-suporte, por sua vez, é uma espécie de auxiliar nominal que serve apenas para veicular as marcas gramaticais de tempo-modo-aspecto e número-pessoa, as quais não podem ser veiculadas pelo nome, devido à sua própria morfologia. As relações sintático-semânticas que se estabelecem entre o verbo e os outros constituintes da construção, sobretudo com relação ao nome predicativo, são diferentes das que se observam em uma construção com verbo pleno e podem ser determinadas por diversas propriedades formais (sintáticas), experimentalmente reprodutíveis.

Diferentes testes podem ser usados para identificar as propriedades definitórias das CVS (RANCHHOD, 1990; BAPTISTA, 2005). O principal teste, que representa uma propriedade necessária e suficiente, é a estreita relação entre o Npred e o sujeito da construção (e.g. Pelé deu um chute na bola, interditando a construção *Pelé deu um chute do Neymar na bola ${ }^{1}$ ). Essa relação é da mesma natureza semântica que a relação existente entre o verbo e seu sujeito, em um predicado verbal (Pelé chutou a bola). Por essa propriedade, alguns verbos, tais como conceder auxílio, aplicar golpe, meter chute, apresentar desculpas e outros, podem ser considerados Vsup. Essas variantes estilísticas apresentam propriedades idênticas às dos Vsup elementares (dar, estar Prep, fazer, haver, ser (de), ter) e são determinadas pelo nome predica- 
tivo, que as seleciona para seu suporte. Ao contrário dos Vsup elementares com uma distribuição mais lata e semanticamente mais neutros, estas variantes têm uma distribuição mais estrita e veiculam diferentes matizes aspectuais e estilísticos, constituindo um importante recurso expressivo da língua.

Além desse teste, há outros que podem ser indicativos de CVS, tais como: (i) a substituição da construção com Vsup por um verbo pleno correspondente (e.g. dar um abraço = abraçar, ou dar um beijo = beijar); (ii) as restrições sobre os determinantes (e.g. Ana deu uma passeada no parque, interditando a construção *Ana deu minha passeada no parque); (iii) a descida do advérbio, que permite que um advérbio modificador de um verbo numa construção verbal "desça", sob a forma de adjetivo correspondente, para a posição de modificador do nome predicativo na construção nominal equivalente (e.g. Rui chutou fortemente a bola $=$ Rui deu um chute forte na bola); dentre outros testes. Para uma visão mais geral sobre CVS, veja-se, dentre outros, Gross (1981, 1998), Giry-Schneider (1978, 1987), Meunier (1981), Vivès (1983), Ranchhod (1990) e Baptista (2005).

As CVS podem admitir transformações específicas, tais como a conversão, a passiva, a simetria ou ainda a possibilidade de formar construções causativas.

A conversão (GROSS, 1982, 1989) é uma operação formal (ou transformação) que estabelece uma relação não-orientada de equivalência sintática e semântica (parafrástica) entre duas frases elementares. Essa operação sintática "executa a permuta dos argumentos em torno do núcleo predicativo da frase sem alterar seu significado global, é semelhante à passiva das construções verbais" (BAPTISTA, 2005, p.184). A construção standard tem orientação ativa (O Rui deu um esclarecimento à Ana), em que o agente da ação se encontra alinhado com a função sintática de sujeito, enquanto a construção conversa possui orientação passiva (A Ana recebeu um esclarecimento por parte do Rui), estando na posição de sujeito o tema, o paciente ou o objeto da ação, enquanto o agente fica alinhado na posição de complemento preposicional da construção.

A transformação passiva já foi longamente descrita nas gramáticas e, por isso, não será explicada em pormenor. Nas construções nominais, a transformação passiva funciona da 
mesma forma como nas construções verbais: a frase está na voz ativa quando o sujeito é o agente da ação (O Rui deu um esclarecimento à $A n a$ ) e está na voz passiva quando o sujeito da frase é o tema, paciente ou objeto - neste caso, o nome predicativo (O esclarecimento foi dado por Rui à Ana).

Já a simetria (BAPTISTA, 2005) é uma propriedade de certas construções em que se verifica que dois argumentos de um predicado desempenham, relativamente ao núcleo predicativo, o mesmo papel semântico. Por essa razão, os argumentos podem trocar de posição relativa e/ou serem coordenados, sem que isso altere o significado das frases resultantes, e.g. $O$ Rui fez um acordo com a Ana = A Ana fez um acordo com o Rui= O Rui e a Ana fizeram um acordo. A simetria observa-se tanto em construções nominais, como no exemplo acima, como em construções verbais e adjetivais.

Além dessas propriedades transformacionais, refira-se também à possibilidade de construir frases causativas a partir de CVS elementares, envolvendo um verbo com um estatuto gramatical particular, a que Gross (1981, p.23) chamou verbo-operador causativo (VopC). Grande parte das CVS que admitem ter como Vsup das respectivas construções de base autorizam igualmente a formação de construções causativas com os verbos-operadores causativos dar e/ou fazer. Por exemplo, considera-se que a construção A Ana tem um grande medo do escuro está na base de frases causativas como $O$ incidente traumático deu na Ana um grande medo do escuro. As construções causativas não são consideradas construções de base porque podem ser desdobradas em dois predicados semânticos: um que exprime um estado (ter medo) e outro que veicula uma relação semântica de causa (dar), ligando o constituinte que expressa essa causa (incidente) e a frase de base.

Neste trabalho, foram adotados os princípios teórico-metodológicos do modelo do Léxico-Gramática (GROSS, 1975, 1981), segundo os quais a unidade mínima de análise linguística é a frase simples, que contém um predicado semântico de base e seus argumentos (sujeito e complementos essenciais). Para caracterizar uma construção ou fenômeno linguístico, é preciso descrever sistematicamente suas propriedades estruturais, distribucionais e transformacionais, pois verifica-se que, apesar de certas regularidades, cada unidade lexical de 
uma língua possui uma gramática própria. Tal questão leva à adoção de uma abordagem descritivista e taxonômica, em que se procura sistematicamente contrastar as propriedades dos itens lexicais e organizar os dados em conjuntos empírica e teoricamente consistentes.

\section{Recolha dos candidatos a CVS}

Os pares de Vsup e Npred candidatos a CVS foram extraídos de três matrizes do Léxico-Gramática (BARROS, 2014; SANTOS-TURATI, 2012; RASSI et al., 2014) e somam cerca de 5.800 Npred. Todos esses dados foram descritos nos moldes do Léxico-Gramática (GROSS, 1975, 1981), em matrizes binárias: nas linhas, constam as entradas lexicais - neste caso, os nomes predicativos; e, nas colunas, as propriedades sintáticas das construções. As propriedades sintáticas descritas nas três matrizes (uma para cada verbo-suporte) são: (i) propriedades estruturais (número de argumentos, classe sintática, tipo de preposição que introduz os complementos essenciais e tipo de determinante selecionado pelo Npred); (ii) propriedades distribucionais (tipo de sujeito e tipo de complemento: humano, não-humano, parte do corpo, nome locativo, oração completiva (finita ou infinitiva), oração factiva, etc.); e (iii) propriedades transformacionais (simetria, conversão, possibilidade de formação de grupo nominal, redução do Vsup, variantes de Vsup, etc.). Na intersecção de cada linha com cada coluna, marca-se "+" ou "-" para indicar respectivamente a aceitabilidade ou inaceitabilidade da propriedade para essa dada construção. Esse formalismo, além de facilitar a visualização, a comparação e o tratamento dos dados, também pode ser usado em aplicações de Processamento Automático de Língua Natural (PLN).

Foram recolhidas, ao todo, $4.668 \mathrm{CVS}$ diferentes, considerando-se 45 variantes dos Vsup elementares ter, fazer e dar e cerca de 3.200 nomes predicativos diferentes. Essa lista constitui um inventário de CVS que pode ser usado para fins computacionais ou servir como ponto de partida para futuros trabalhos que visem a identificar ou extrair automaticamente CVS de corpora. A seção seguinte apresenta a metodologia usada para extrair esses pares candidatos a CVS a partir de corpus. 
2 Disponível em <http://www-igm univ-mlv.fr/ unitex/>

3 Os grafos são um tipo de representação formal utilizado em abordagens estruturais para a descrição de línguas e é também um recurso disponível na ferramenta UNITEX, utilizada neste trabalho. Os grafos são autômatos de estados finitos e são lidos da esquerda para a direita: a seta mais à esquerda indica o primeiro estado do grafo e o quadrado dentro de um círculo (mais à direita) indica o estado final. Entre os estados inicial e final, existem vários estados intermediários, que são representados pelas caixas (retângulos horizontais). Os caminhos entre um estado e outro são indicados por meio de setas. Nos grafos que se seguem, os estados intermediários significam: (i) “@ $\mathrm{A}^{\prime} \mathrm{e}$ “@ $\mathrm{B}$ ” são variáveis que serão preenchidas por Npred e Vsup, respectivamente, a partir da informação constante numa matriz; (ii) " $<$ !V $>$ " indica a negação da categoria verbo, ou seja, naquela posição pode haver qualquer palavra que não seja um verbo. $\mathrm{Na}$ caixa $<$ !V $>$, uma das setas que saem indica um loop, ou seja, a possibilidade de ocorrer uma sequência indefinidamente longa de elementos que não sejam verbos; (iii) "<ser>" corresponde a qualquer forma conjugada do verbo ser; e (iv) "<ADV>" corresponde a qualquer advérbio. Os símbolos "N" (nome) e "Vsup" (verbo-suporte) em vermelho identificam as variáveis usadas na saída (output), nomeadamente as balizas e as etiquetas "[CVS: ... ] (\$Vsup\$,\$Npred\$)" a ser visualizada no output, que é a saída do sistema. No caso deste grafo (Fig. 1), o output será, por

\section{Extração dos candidatos a CVS a partir de corpus}

Das 3 matrizes descritas na seção anterior, foram utilizadas as informações de verbo-suporte elementar, variantes de verbo-suporte e verbo-suporte converso, além da coluna dos nomes predicativos. A fim de identificar todas as construções em corpus, recorreu-se ao software UNITEX ${ }^{2}$ (v. 3.1) (PAUMIER 2003), uma plataforma open-source de desenvolvimento de recursos linguísticos e processamento automático de texto, baseada em tecnologia de máquinas de estados finitos. As informações sobre a co-ocorrência dos verbos com os nomes de cada construção foram, posteriormente, intersectadas com grafos de referência ${ }^{3}$.

Assim, foram criados dois grafos de referência: (i) um a ser utilizado com os verbos-suporte fazer e dar (Fig. 1), porque leva em consideração a forma passiva das construções; e (ii) outro grafo a ser utilizado com os Npred que selecionam o verbo ter, que não considera a forma passiva porque as construções com ter não admitem apassivação.

Figura 1 - Grafo de referência para identificação das CVS com os verbos fazer e dar

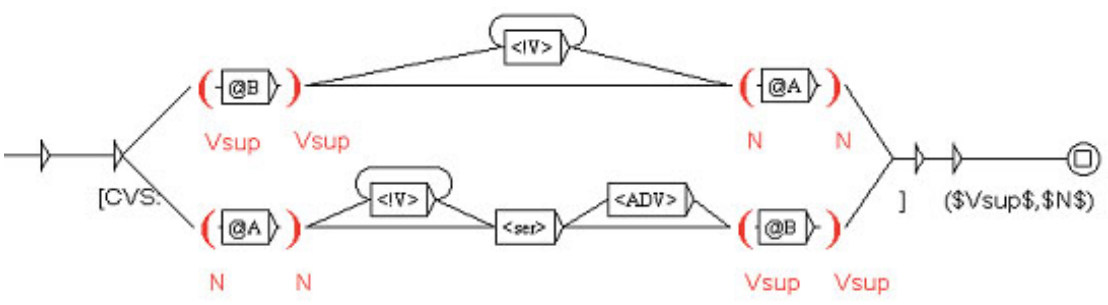

As notações e códigos usados nesse grafo estão explicadas na nota iii (ao fim do texto). Esse grafo possui dois caminhos. A partir da etiqueta "[CVS:", o primeiro caminho se lê: instancia-se o verbo-suporte, seguido imediatamente de um nome predicativo ou seguido de qualquer número de palavras, desde que não sejam verbos; em seguida instancia-se o nome predicativo e fecha-se a etiqueta CVS com "]". No segundo caminho, que prevê a inversão da ordem de verbo e nome, a fim de dar conta dos casos de construções passivas, lê-se: 
exemplo: “O catálogo da exposição de Duchamp no Palazzo Grassi de Veneza, encerrada em julho último, [CVS: dá as primeiras pistas] (dá,pistas)." Trata-se de um tipo particular de grafos diretos acíclicos (directed acyclic graphs), que se usam para processar tabelas de dados, linha a linha, e que fazem referência às colunas dessas tabelas através de variáveis. Nesses grafos, definem-se os padrões combinatórios a procurar nos textos e, posteriormente, o sistema gera, para cada linha, o correspondente transdutor que permite procurar esses padrões nos textos e, em caso de emparelhamento, modificar o texto (inserir balizas, por exemplo).

4 Os verbos estar, ficar e outros auxiliares das passivas de estado não foram considerados neste momento.

5 A possibilidade de o verbo ter integrar uma construção passiva (no segundo caminho do subgrafo) deve-se ao caráter automático do processo de geração do grafo. Uma vez que este é usado para reconhecimento (e não para geração), tal não constitui um problema para os objetivos deste artigo. instancia-se o nome predicativo, que pode ser seguido imediatamente do verbo $\mathrm{ser}^{4}$ ou pode haver entre eles um número indefinido de palavras que não sejam verbos; o verbo ser pode ainda ser seguido imediatamente do Vsup ou haver, entre eles, algum advérbio; no fim, fecha-se a etiqueta CVS com "]". Foi construído um grafo semelhante (considerando apenas o primeiro caminho do grafo da Fig. 1) para as construções com ter, que não admitem apassivação.

Ao intersectar as matrizes com os grafos de referência, o sistema UNITEX produz um subgrafo de resultado para cada linha da matriz que foi instanciada por uma combinação de Vsup e Npred. Assim, o número de subgrafos corresponde ao número de linhas das matrizes. A Fig. 2 mostra um exemplo de um dos subgrafos de resultados gerado automaticamente pelo UNITEX.

Figura 2 - Subgrafo 0398 da matriz dos Npred com dar

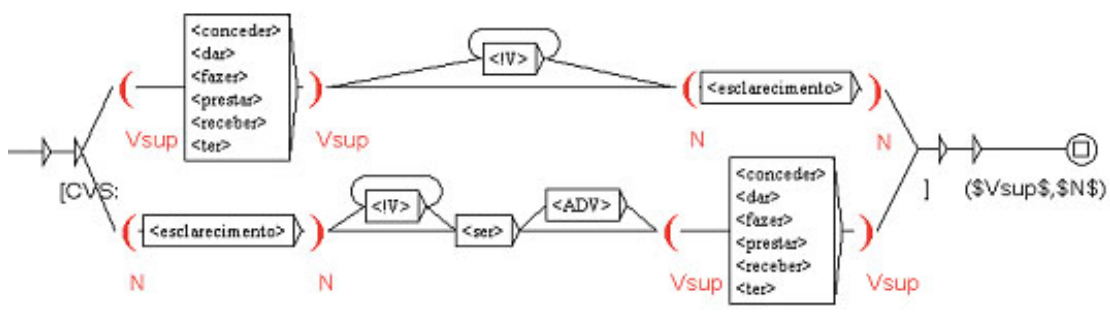

Nesse subgrafo, representam-se as combinações determinadas pelo nome predicativo esclarecimento, que pode selecionar o verbo-suporte elementar dar ou suas variantes estilísticas e/ ou aspectuais conceder, fazer e prestar, na construção standard, e selecionar os verbos-suporte conversos receber e ter, na construção conversa. No caminho inferior do grafo, apresentam-se as construções passivas correspondentes ${ }^{5}$.

Além de todos os subgrafos de resultados, o UnITEX também gera automaticamente um grafo único de resultados, que integra todos os subgrafos. Esse grafo de resultados foi aplicado ao corpus PLN.Br Full (BRUCKSCHEN et al., 2008), que é um corpus jornalístico do jornal Folha de São Paulo, com 29.014.089 tokens, distribuídos por 103.080 mil textos. Somando-se os re- 
6 O termo type será utilizado, neste trabalho, para referir os tipos diferentes de pares de Vsup e Npred. Já o termo token se refere à quantidade de instâncias do mesmo objeto. $\mathrm{O}$ corpus apresenta 121.198 tokens (pares de Vsup e Npred iguais e/ou diferentes), mas apenas 4.668 types (pares de Vsup e Npred diferentes). sultados da aplicação das 3 matrizes, o UNITEX retornou 177.287 frases. Algumas dessas frases foram extraídas em duplicado porque, muitas vezes, o mesmo nome predicativo constava em duas ou três matrizes com as mesmas variantes de Vsup; portanto, excluindo-se as duplicadas, restaram 131.734 frases. As frases que foram mal segmentadas pelo sistema (por problemas de pontuação, sobretudo) somam 10.536 frases ( $8 \%$ dos dados) e foram excluídas do corpus de referência. Restaram, assim, 121.198 frases a serem anotadas.

\section{A seleção da amostra}

O universo total deste objeto de estudo consiste em 121.198 frases. Desse universo, foi selecionada uma amostra estratificada a ser anotada, que é proporcional à quantidade de ocorrências de cada par (Vsup, Npred) e, ao mesmo tempo, que leva em consideração a diversidade das combinações. A amostra foi estratificada em 3 blocos: (i) a amostra global, que recuperou pelo menos um caso de todos os pares que tenham 21 ocorrências ou mais; (ii) a amostra intermédia, que corresponde aos pares (Vsup, Npred), que tenham, no mínimo 2, e, no máximo, 20 ocorrências no corpus; e (iii) os hapax legomena, que são os pares que possuem uma única ocorrência no corpus.

A Tabela 1 apresenta a distribuição dos pares candidatos a CVS em cada bloco da amostra. Ressalte-se que o número (e porcentagem) de frases aparece apenas para a amostra global porque corresponde às frases que foram, de fato, anotadas. A amostra intermédia e os hapax legomena serão selecionados e anotados em trabalhos futuros. A Tabela 1 indica também o número de types ${ }^{6}$ em cada bloco e sua porcentagem em relação ao total, além da porcentagem do corpus que é abrangido por cada bloco.

Tabela 1 - Distribuição da amostra

\begin{tabular}{cccccc}
\hline Amostra & $n^{0}$ frases & $\%$ frases & $n^{0}$ types & $\%$ types & Cobertura do corpus \\
\hline Amostra global & 2.646 & $2,18 \%$ & 1.130 & $24,2 \%$ & $84,85 \%$ \\
\hline Amostra intermédia & --- & --- & 2.537 & $54,3 \%$ & $14,30 \%$ \\
\hline Hapax legomena & --- & --- & 1.001 & $21,5 \%$ & $0,85 \%$ \\
\hline TOTAL & 121.198 & $100 \%$ & 4.668 & $100 \%$ & $100 \%$ \\
\hline
\end{tabular}


Como se pode perceber, a amostra global abrange 2.646 frases, ou seja, 2,18\% do conjunto total (121.198 frases). Dos 4.668 types de pares, a amostra global conta com 1.130 types, o que corresponde a $24,2 \%$ dos pares diferentes e $84,85 \%$ das sentenças do corpus. A amostra intermédia considera outros 2.537 types, que equivalem a 54,3\% dos types do universo, mas apenas $14,30 \%$ das sentenças do corpus. O último bloco da amostra compreende os hapax legomena, contendo 1.001 hapax, que correspondem a $21,5 \%$ do total de types e cobrem $0,85 \%$ do corpus.

Conforme apontado anteriormente, apenas o primeiro subconjunto de dados, que corresponde à amostra global, foi anotado. Nesse sentido, o conjunto de frases que constituem o golden standard das CVS em Português, ou seja, o conjunto anotado que pode ser utilizado para avaliação de diferentes métodos de identificação, classificação ou processamento de CVS, foi estabelecido com base somente na amostra de quase $25 \%$ do total de types (Vsup, Npred), o que cobre $84,85 \%$ do corpus total.

\section{A anotação da amostra}

A anotação da amostra global (2.646 frases) foi feita manualmente por 5 anotadores falantes nativos do Português e especialistas em CVS, usando a ferramenta CorpusAnnotator (SUÍSSAS, 2014). Essa ferramenta foi desenvolvida em Java e precisa de dois arquivos com extensão ".txt" para funcionar: (i) um arquivo com todas as frases a serem anotadas (uma frase por linha); e (ii) um arquivo de parametrização com todas as formas de singular e plural dos nomes predicativos, a fim de assinalar em cada frase a palavra-alvo da anotação, neste caso, o Npred.

A anotação consistiu em assinalar, para cada frase, um código (convencional) que corresponde ao tipo de construção sintática indicada pelo par (Vsup, Npred), que aparece entre parênteses no início de cada frase. As etiquetas disponíveis são:

CVS-STANDARD - para as construções com verbo-suporte standard Ex.: (dar, tapa) A Ana deu um tapa no Rui

CVS-CONVERSA - para as construções com verbo-suporte converso Ex.: (levar, tapa) O Rui levou um tapa da Ana 
VOPC - para as construções com verbo-operador causativo

Ex.: (dar, medo) O vento sombrio deu medo na Ana

Ex.: (fazer, medo) O vento sombrio fez com que a Ana tivesse medo

OTHER - para qualquer outro tipo de construção (com verbo pleno, expressão fixa, ou outros)

Ex.: (fazer, academia) Rui fez (= construiu) uma academia [verbo pleno]

Ex.: (dar, tiro) O governo deu um tiro no próprio pé [expressão fixa] Ex.: (ter, controle) Rui tem Max sob seu controle [verbo-operador de ligação]

As diferenças entre as construções standard e as construções conversas serão abordadas na seção 7.1. As construções causativas, formadas pelo verbo-operador causativo (Gross, 1981, pp.23-38) e um nome predicativo serão explicadas na seção 7.2. As construções com o verbo-operador de ligação (Gross, 1981, pp.30-32) serão analisadas em 7.3. Já as expressões fixas serão definidas e explicadas na seção 7.4.

As anotações foram tabuladas em 5 colunas (uma para cada anotador) e, em seguida, foram comparadas por meio da ferramenta ReCal 0.1 Alpha for3+ Coders tool' ${ }^{7}$, que foi usada para calcular a concordância entre os anotadores. A Tabela 2 indica a concordância entre cada par de anotadores.

Tabela 2 - Concordância entre pares de anotadores

7 Disponível em $<$ http://dfreelon.org/ recal/recal3.php>

\begin{tabular}{cccccc} 
Anotador & 1 & 2 & 3 & 4 & 5 \\
\hline 1 & --- & $83,35 \%$ & $\mathbf{8 4 , 7 1 \%}$ & $84,28 \%$ & $80,39 \%$ \\
\hline 2 & --- & --- & $81,40 \%$ & $80,55 \%$ & $\mathbf{7 3 , 3 1 \%}$ \\
\hline 3 & --- & --- & --- & $84,05 \%$ & $78,41 \%$ \\
\hline 4 & --- & --- & --- & --- & $77,55 \%$ \\
\hline 5 & --- & --- & --- & --- & -- \\
\hline
\end{tabular}

Como se pode depreender da Tabela 2, as concordâncias entre anotadores variam pouco, desde a mais baixa $(73,31 \%)$, entre os anotadores 2 e 5 , até a mais alta $(84,71 \%)$, entre os anotadores 1 e 3 . A concordância média entre todos os anotadores foi de $80,8 \%$. 


\section{Resultados}

Após a anotação, procedeu-se à análise quantitativa dos dados. A Tabela 3 apresenta a proporção relativa à quantidade de frases com concordância total ou diferentes medidas de concordâncias parciais entre os anotadores.

Tabela 3 - Quantidade de frases com concordância total e concordâncias parciais

\begin{tabular}{cccc}
\hline$N^{\circ}$ anotadores & \% anotadores & $N^{0}$ frases & $\%$ frases \\
\hline 5 & $100 \%$ & 1.584 & $59,86 \%$ \\
\hline 4 & $80 \%$ & 627 & $23,69 \%$ \\
\hline 3 & $60 \%$ & 318 & $12,01 \%$ \\
\hline 2 & $40 \%$ & 42 & $1,62 \%$ \\
\hline--- & Excluidas & 75 & $2,83 \%$ \\
\hline TOTAL & & 2.646 & $100 \%$ \\
\hline
\end{tabular}

Quase 60\% das frases tiveram concordância entre todos os 5 anotadores. A soma das concordâncias total e parciais pela maioria (3, 4 ou 5 anotadores) corresponde a $96 \%$. Outras 75 frases $(2,83 \%)$ foram excluídas da amostra porque foram mal extraídas ou não apresentavam contexto suficiente para que os anotadores pudessem anotar.

Se, para o golden standard, forem consideradas apenas as 1.584 frases cuja concordância foi total entre os 5 anotadores (100\% de concordância), a distribuição, por categoria, será a seguinte (Tabela 4):

Tabela 4 - Distribuição das frases com concordância total

\begin{tabular}{ccc} 
Categoria & No frases & $\%$ frases \\
\hline CVS-STANDARD & 1202 & 76,4 \\
\hline CVS-CONVERSA & 92 & 5,8 \\
\hline OTHER & 280 & 17,8 \\
\hline TOTAL & 1.584 & $100 \%$ \\
\hline
\end{tabular}


A grande maioria das frases $(76,4 \%)$ correspondem a CVS standard (de orientação ativa). Apenas 5,8\% das CVS são construções conversas (de orientação passiva). Outras 280 frases da amostra não correspondem a construções com verbo-suporte. Vale ressaltar que não houve nenhuma frase que tenha sido anotada como VopC (construção com verbo-operador causativo) pela totalidade dos anotadores.

Por outro lado, se forem consideradas todas as frases cuja concordância foi de $60 \%, 80 \%$ ou $100 \%$, ou seja, tiveram concordância da maioria ou totalidade dos anotadores, o golden standard será constituído de 2.529 frases. As frases que tiveram apenas $40 \%$ de concordância, ou seja, foram anotadas com a mesma etiqueta por apenas dois anotadores foram excluídas do golden standard. A Tabela 5 apresenta a distribuição das frases com concordâncias parcial (por 3 ou 4 anotadores) e total (pelos 5 anotadores), divididas por categoria.

Tabela 5 - Distribuição das frases com concordância entre a maioria dos anotadores

\begin{tabular}{ccc}
\hline Categoria & $N^{0}$ frases & $\%$ \\
\hline CVS-STANDARD & 1.835 & 72,6 \\
\hline CVS-CONVERSA & 206 & 8,1 \\
\hline VOPC & 6 & 0,2 \\
\hline OTHER & 482 & 19,1 \\
\hline TOTAL & 2.529 & $100 \%$ \\
\hline
\end{tabular}

Como se pode notar, a grande maioria das frases $(72,6 \%)$ que compõem o golden standard possuem CVS de orientação ativa (CVS-standard). Apenas $8,1 \%$ das frases são de orientação passiva (CVS-conversa). O corpus de referência, anotado e revisado, possui, portanto, 2.041 sentenças, que correspondem à soma do número de frases com CVS standard e conversa. As 6 construções com verbo-operador causativo (VopC), bem como as 482 frases anotadas como "OTHER" não foram integradas ao golden standard, já que não correspondem a construções com verbo-suporte. Contudo, esse conjunto está disponível, na medida em que constituem instâncias negativas (contraexemplos), que podem ser utilizadas para treinar e avaliar diferentes métodos de identificação, classificação e processamento de CVS. 


\section{Discussão de casos particulares}

A maioria dos pares candidatos a CVS $(59,86 \%)$ conforme apresentado na Tabela 3, não geram discordância entre os anotadores quanto ao seu estatuto. Há, no entanto, alguns pares cuja discordância é considerável. Nesta seção, serão apresentados casos em que houve discordância entre os anotadores e os casos em que a discordância não foi alta, porém foi sistemática. De maneira geral, esses casos particulares não se referem a um Npred específico, mas a grupos de Npred que possuem comportamentos sintático e semântico semelhantes.

\subsection{Construções standard e construções conversas}

Essa distinção está ligada à possibilidade de as CVS apresentarem uma construção standard (de orientação ativa) e uma construção conversa (de orientação passiva), ligadas pela operação de Conversão (G. GROSS, 1982, 1989; BAPTISTA, 1997; RASSI et al., 2015).

Os nomes predicativos relacionados à área médica podem ser interpretados sob duas óticas diferentes: do ponto de vista do agente (por exemplo, o médico) ou do ponto de vista do paciente. Trata-se de pares como (fazer acompanhamento), (fazer) realizar cirurgia), (fazer consulta), (fazer diagnóstico), (fazer/realizar exame), (fazer/realizar operação), (fazer terapia), (fazer/realizar tratamento), e outros. Os seguintes exemplos ilustram o fenômeno:

(1) (fazer, exame) O médico fez um exame no paciente-STANDARD (1a) = O médico examinou o paciente

(2) (fazer, exame) O paciente fez um exame no hospital público - CONVERSO

$(2 a)=($ submeter-se $\boldsymbol{a}$, exame $)$ O paciente se submeteu a um exame no hospital público - CONVERSO

$(2 b)=O$ paciente foi examinado no hospital público (pelo médico)

(3) (fazer, tratamento) O médico faz o tratamento dos pacientes gratuitamente - STANDARD

(3a) = O médico trata os pacientes gratuitamente

(4) (fazer, tratamento) Os pacientes fazem o tratamento gratuitamente - CONVERSO

$(4 a)=($ submeter-se $a$, tratamento $)$ Os pacientes se submetem ao tratamento gratuito - CONVERSO

$(4 b)=$ Os pacientes são tratados gratuitamente (pelo médico) 
Barros (2014, pp. 99-100) havia apontado para a distinção entre os papéis semânticos de agente e paciente ocupando a posição sujeito, o que poderia auxiliar na distinção desses casos. Identificando-se os papéis semânticos dos argumentos, seria possível identificar também as diferentes orientações de sentido (ativo ou passivo) expressas pela construção.

O fato de um mesmo par (e.g. fazer exame ou fazer tratamento) poder ser classificado ora como CVS-standard ora como CVS-conversa gerou discordância entre os anotadores. A decisão adotada, nesses casos, consistiu em verificar a orientação de sentido (ativo ou passivo) da ação, por meio da aplicação de testes: transforma-se a frase nominal em uma frase verbal, mantendo o mesmo sujeito, e verifica-se se essa frase verbal está na voz ativa ou na voz passiva. Se estiver na voz ativa, a construção nominal é standard; se estiver na voz passiva, a construção nominal é conversa.

Uma análise semelhante à dos Npred da área médica pode ser feita para alguns nomes predicativos relacionados ao ensino, tais como fazer aula, fazer curso, fazer/realizar prova, fazer/ realizar teste, fazer treino e outros.

A expressão dar aula forma construções tipicamente standard, enquanto a expressão ter aula forma construções tipicamente conversas. Quando esses Npred são associados ao Vsup fazer, tanto podem formar construções standard quanto construções conversas: se é o professor o sujeito, quem prepara a aula para os alunos, (fazer, aula) é CVS-standard; no entanto, se é o aluno o sujeito, quem assiste à aula do professor, (fazer, aula) é uma CVS-conversa; naturalmente, só conhecendo essa informação de natureza extralinguística é possível determinar com exatidão de qual construção se trata:

(5) O professor fez (= deu) uma aula sobre fungos

(6) O aluno da graduação fez (= teve) aulas de Matemática

O par fazer empréstimo não pertence ao mesmo campo semântico dos nomes relacionados ao estudo, mas deve ser analisado da mesma forma: fazer empréstimo pode ser ora CVS-standard ora CVS-conversa. Quando se refere a emprestar algo a alguém, o par fazer empréstimo é uma construção standard; quando se refere a pegar algo emprestado de alguém, o par fazer empréstimo é converso. 
(7) (fazer, empréstimo) Em 2001 Valério fez empréstimo de $R$ \$

250 mil para o ex-tesoureiro - STANDARD

(7a) = Em 2001 Valério emprestou $R$ \$ 250 mil para o ex-tesoureiro

(8) (fazer, empréstimo) Em 2001 Valério fez empréstimo de $R$ \$ 250 mil no banco - CONVERSO

(8a) = Em 2001 Valério pegou emprestado $R \$ 250$ mil no banco

O primeiro caso (7), retirado do corpus, é tipicamente uma CVS-standard, enquanto o segundo caso (8), construído a partir do primeiro, é uma $C V S$-conversa. A mesma confusão se verifica com os dois sentidos veiculados pelo verbo pleno emprestar. Em Português do Brasil, emprestar admite duas regências: (i) emprestar para, que tem orientação ativa, e (ii) emprestar de, que tem orientação passiva e significa pegar emprestado.

Assim como no caso dos Npred relacionados ao estudo, o estatuto do Npred empréstimo é relativamente pacífico quando associado ao verbo dar (standard) e ao verbo ter (converso). Essa ambiguidade se verifica apenas com relação ao Vsup fazer.

\subsection{Construções com verbo-operador causativo}

As construções com verbo-operador causativo (VopC; $\mathrm{M}$. GROSS, 1981) se distinguem das construções com verbo-suporte e dos verbos plenos (ou distribucionais) por várias propriedades, de que se podem destacar como principais:

1. o preenchimento lexical da posição sujeito nas construções com verbo-operador causativo sofre fracas restrições de seleção, constituindo aquilo que M. Gross (1981) designou por uma posição de nome não-restrito (Nnr), ou seja uma posição sintática (geralmente sujeito) que pode ser preenchida lexicalmente por nomes de tipo humano, não-humano e até orações completivas, nomeadamente factivas, e que recebe a interpretação de causa, e.g. (O Pedro $+A$ atitude do Pedro $+O$ fato de o Pedro ter feito isso + Isso) deu medo à Ana;

2. frequentemente, o verbo-operador causativo (dar, fazer e outros) "absorve" o Vsup da construção de base, reestruturando-a e colocando o respectivo sujeito na posição de complemento (e.g. Isso deu/fez \# A Ana tem medo = Isso deu / fez medo na Ana); o VopC fazer (mas não o verbo dar) pode, porém, aplicar-se à frase sem que esta seja reestruturada 
e permitindo, portanto, a manutenção do Vsup da frase de base (e.g. Isso fez a Ana ter medo);

3. o verbo-operador causativo pode comutar com outros verbos que, de forma mais evidente, expressam um valor causativo, tais como causar, provocar, fazer com, etc. (e.g. Isso causou medo na Ana);

4. os verbos-operadores causativos, embora tenham um largo espectro distribucional, não têm uma distribuição própria, sendo a sua seleção dependente da construção do nome predicativo da CVS à qual se aplicam.

Assim, alguns Npred, quando combinados com o verbo ter, formam construções de base, em que esse verbo é um Vsup. Por outro lado, os mesmos Npred, quando combinados com os verbos dar ou fazer, devem ser analisados como constituindo construções causativas com verbo-operador, como se demonstra a seguir:

(9) (ter, ciúmes) A Ana tem ciúmes do Rui

(9a) $[$ Causativo] $=($ fazer, ciúmes $)(O$ Rui + Isso $)$ fez ciúmes na Ana

(10) (ter, alegria) A Ana tem muita alegria

(10a) $[$ Causativo $]=($ dar, alegria $)(O$ Rui + Isso $)$ deu muita alegria à Ana

A par dessas construções causativas mais típicas, alguns Npred, que geralmente formam CVS com o verbo dar, podem, em situações particulares, combinar-se com o mesmo verbo em construções que deverão ser classificadas como causativas. Esses Npred, tais como dica, explicação, informação e outros, podem admitir como sujeito um nome não-restrito (Nnr):

(11) (dar, explicação) A Ana deu uma explicação ao Rui sobre esse fenômeno

\# (11a) (dar, explicação) (?Ana + O aumento da temperatura $+O$ desmatamento da Amazônia $+O$ fato de os homens poluírem mais + Isso) deu uma explicação sobre o aquecimento global (à sociedade)

Em rigor, a frase (11) é uma CVS, ao passo que a frase (11a) deve ser classificada como uma construção causativa, já que atende às propriedades elencadas anteriormente. O sujeito humano de (11a) é praticamente inaceitável nessa construção com interpretação causal. Contudo, dada a possibilidade de 
ambiguidade entre a interpretação agentiva e a interpretação causal de um sujeito humano nesse tipo de construções, a frase será classificada como uma CVS com base nos seguintes critérios: (i) a expressão corresponde a uma ação (logo, o sujeito recebe o papel semântico de agente); e (ii) o sujeito, com interpretação agentiva, é também de natureza volitiva e a ação realizada é intencional, o que pode ser atestado por meio da inserção, na frase, de algum advérbio, como de propósito, intencionalmente, propositalmente, voluntariamente, etc. (11b):

$(11 b)=$ A Ana, (intencionalmente + voluntariamente + propositalmente), deu uma explicação incorreta ao Rui sobre esse fenômeno

Além de o predicado dar uma explicação em (11b) referir-se a uma ação, também é possível inserir qualquer um desses advérbios logo após o sujeito. Note-se que esse teste não é aceitável em construções causativas, como, por exemplo, (11c):

(11c) (dar, explicação) *(O aumento da temperatura $+O$ desmatamento da Amazônia + O fato de os homens poluírem mais + Isso) deu, (intencionalmente + voluntariamente + propositalmente), uma explicação sobre o aquecimento global (à sociedade)

\subsection{Construções com verbo-operador de ligação}

Muitos nomes predicativos, tais como notícia, orientação, informação, explicação, opinião, solução, resposta, exemplo, definição, dica, pista, sugestão, argumento, parecer etc., associados ao Vsup ter, admitem duas interpretações diferentes, uma de sentido passivo, em (12), e outra de sentido ativo, em (13):

(12) (ter, notícia) Zé teve uma notícia ruim <quando Ana lhe contou sobre a morte do pai>

(13) (ter, notícia) Zétem uma notícia ruim <para dar à/para Ana>

Os tempos verbais, em rigor o aspecto "pontual" do pretérito perfeito, em (12), e o aspecto "durativo" do presente (ou do imperfeito), em (13), permitem distinguir esses dois empregos. O exemplo (12) é menos controverso, sendo claramente considerado como uma CVS-conversa, já que tem como contraparte a construção standard:

(12a) Alguém deu uma notícia ruim ao Zé 
O estatuto dessa construção conversa não gerou dúvidas entre os anotadores. Em contrapartida, o mesmo par (ter, notícia), em (13), parece ter um estatuto especial, pois se assemelha a uma construção de orientação ativa (e.g. Zé deu uma notícia ruim à Ana), mas a ação não chega a se concretizar (aspecto imperfectivo).

O predicado de base em (13) é dar uma notícia, já que pode ser reconstituído na oração infinitiva introduzida por para (e.g. Zé tem uma notícia ruim para dar à/para Ana). De acordo com Cristina Santos-Turati (comunicação pessoal), o verbo ter, nesse sentido, serve apenas para ligar o argumento (Zé) ao predicado dar uma notícia. Esse argumento (Zé) não é novo, ele já existia na frase de base. Nessas condições, o verbo ter, em (13), tem um estatuto de um verbo-operador de ligação (VopL; M. GROSS, 1981; RANCHHOD, 1990), ligando um argumento (Zé) a uma frase de base, embora esse argumento já esteja presente nela. Ao mesmo tempo, ele "absorve" o verbo-suporte dar da construção de base. Há, no entanto, outras especificidades que distinguem (13) de outras construções com VopL, tais como a possibilidade da reconstituição do Vsup reduzido numa oração introduzida por para, mas essa análise não será feita em profundidade neste trabalho, remetendo para o estudo da autora (SANTOS-TURATI, 2015, em preparação).

Zé tem \# Zé dá uma notícia ruim para Ana

(13) Zé tem uma notícia ruim para (Ana + dar à/para Ana)

O mesmo fenômeno pode ser observado em vários outros Npred associados ao verbo ter, tais como dica, explicação, informação, opinião, orientação, pista, solução, entre outros. Esses Npred, quando combinados com o verbo ter, geralmente dão origem a construções conversas, deriváveis de CVS standard com o verbo dar, como é o caso de (14) a (16). Pontualmente, porém, terão de ser classificados como construções com verbo-operador de ligação (VopL), como é o caso de (17) a (19) (exemplos selecionados a partir do corpus de referência):

(14) (ter, notícia) Segundo Zeca, o Estado vizinho de Mato Grosso tem "quase uma dezena de usinas instaladas na bacia do Paraguai sem que se tenha tido notícia de um único acidente ambiental" 
(15) (ter, informação) A delegada diz que é importante que os passageiros que sejam furtados ou roubados registrem a ocorrência na delegacia do aeroporto, para que a polícia tenha mais informações sobre o modo como os bandidos agem

(16) (ter, solução) A disputa entre juízes e a direção da liga, que aparentemente teria uma solução rápida, deve durar algumas rodadas

(17) (ter, notícia) O "The Wall Street Journal" tem boas notícias para todos vocês, ratos de sofá

(18) (ter, informação) A página tem informações sobre o clube, fotos e os nomes dos membros

(19) (ter, solução) Quem ousaria dizer que tem a solução para o caso?

7.4 Npred com interpretação não-literal vs. expressões fixas

Houve alguma divergência entre os anotadores na classificação de pares de Vsup e Npred candidatos a CVS nos casos em que o Npred possui significado metafórico (i.e. figurado, não-literal). Alguns anotadores classificaram-nos como CVS-standard e outros como OTHER. Seguem-se alguns desses casos:

(20) (dar, passo) Pior: poucos países estão de fato dando passos firmes para atingir a meta

(21) (dar, tiro) O PT está dando um tiro no próprio pé ao tentar abortar a CPI do caso Waldomiro

(22) (dar, volta) Até lá, não custa nada ter esperança de que pelo menos um grande clube carioca está dando a volta por cima e reconquistando seu lugar de honra na elite do futebol nacional

(23) (fazer, justiça) Somos revolucionários puros, a causa é nobre e a história nos fará justiça

No intuito de sistematizar a anotação, foram considerados os seguintes critérios para distinguir as Expressões Fixas (EF) das CVS: (i) a existência de complementos fixos; (ii) a fixidez do determinante; (iii) o sentido (literal ou figurado) dos complementos; e (iv) a fixidez do verbo $(V)$ e do nome (N1), que remete para a impossibilidade de substituí-los por sinônimos. A Fig. 3 apresenta a chave dicotômica para a distinção entre $E F$ e CVS. 
Figura 3 - Chave dicotômica para a distinção entre $E F$ e CVS

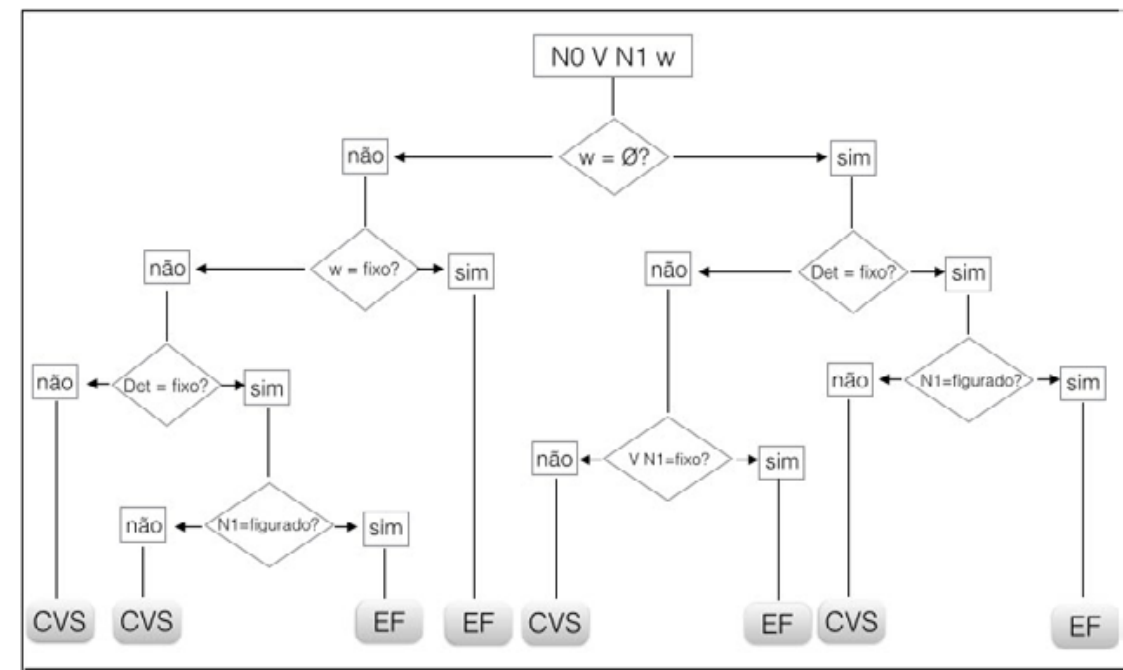

A Fig. 3 deve ser interpretada da seguinte forma:

1. Se a construção possui outro(s) complemento(s) ${ }^{8}$ :

1.1. e, se algum dos complementos é fixo, então trata-se de uma $E F$;

1.2. mas, se o complemento não é fixo, então:

1.2.1. se o determinante é livre, é uma CVS;

1.2.2. mas, se o determinante é fixo:

1.2.2.1. e N1 tem sentido literal, então é $C V S$.

1.2.2.2. e N1 tem sentido figurado, então é $E F$.

2. Se a construção não possui outro(s) complemento(s):

2.1. se o determinante é livre:

2.1.1. e os dois constituintes (verbo e nome) são fixos, então é $E F$;

2.1.2. mas os dois constituintes (verbo e nome) são livres, então é uma $C V S$;

2.2. mas, se o determinante é fixo:

2.2.1. e, se o nome tem uma interpretação literal, então é uma CVS.

8 A existência de outro(s) complemento(s) 2.2.2. e, se o nome tem uma interpretação figurada, então é uma $E F$. 
Para concluir esta seção, analisem-se dois casos aparentemente semelhantes, mas que são diferentes quanto à sua classificação: (fazer, cinema) e (fazer, filme). Esses casos são ainda interessantes por salientarem as diferenças entre as variantes brasileira e europeia. No Português Europeu, além da interpretação literal de "ser ator de filmes", a expressão fazer um filme também tem um valor figurado quando empregue no sentido de "pôr-se a imaginar o que poderia acontecer", geralmente com uma conotação negativa (ou disfórica), sendo considerada, nessa situação, uma EF. Em Português Brasileiro, fazer filme permite apenas a interpretação literal, pelo que corresponde a uma CVS. Pode-se comparar a EF fazer um filme, em PE, com as expressões fixas fazer teatro, fazer drama e fazer cena, em PB, que, em certas situações, significam "agir com exagero".

O par (fazer, filme), na perspectiva tanto do cineasta quanto do ator, é considerado uma $C V S$, pois, na ausência de outros complementos, o Npred filme admite determinante livre. Já o par (fazer, cinema) também não possui outros complementos, além do verbo e do nome, então, seguindo a orientação da chave dicotômica, verifica-se se o determinante é livre ou fixo:

(24) (fazer, filme) Eva fez (um + muitos + algum + seu $+\varnothing)$ filme(s)

(25) (fazer, cinema) Eva fez $\left({ }^{*} u m+{ }^{*}\right.$ muitos $+{ }^{*}$ algum $+{ }^{*}$ seu $+\varnothing)$ cinema

O exemplo (24) admite livremente qualquer determinante, ao passo que (25) exige a ausência de determinante, ou seja, tem determinante fixo. Além da fixidez do determinante, o nome cinema é usado metonimicamente no lugar de "filme exibido no cinema", o que nos permite afirmar que fazer cinema é uma $E F$, ao passo que fazer filme é uma CVS.

Utilizando-se essa chave dicotômica, foi possível identificar 17 ocorrências de Expressões Fixas na amostra anotada, tais como os exemplos de (20) a (23).

\section{Considerações finais}

Este artigo descreveu o processo de constituição de um corpus anotado com informações sobre verbos-suporte e nomes predicativos, a partir da anotação manual de uma amostra das 
121.198 frases extraídas de textos reais em Português do Brasil. Foram recenseadas 4.668 combinações diferentes de pares de Vsup e Npred, que podem ser usadas em tarefas de PLN, tais como análise sintática automática, desambiguação lexical, ou em diversas aplicações, como tradução automática, sumarização automática, sistemas de pergunta e resposta, dentre outras.

Além da lista de $C V S$, foi constituído também um subcorpus do PLN.Br Full, contendo 2.646 frases anotadas e revisadas manualmente, que servirá como corpus de referência para avaliar sistemas automáticos de análise sintática. No futuro, pretende-se utilizar esse corpus para avaliar, em especial, a performance do parser XIP (MOKHTAR, 2002), que é o analisador sintático automático usado na cadeia de processamento do Português STRING (MAMEDE et al., 2012).

\section{REFERÊNCIAS BIBLIOGRÁFICAS}

BAPTISTA, J. Sermão, tareia e facada: uma classificação das expressões conversas dar-levar. In: Seminários de Linguística 1, Faro. Universidade do Algarve, Unidade de Ciências Exactas e Humanas, pp. 5-38, 1997.

Sintaxe dos Predicados Nominais com SER DE.

Lisboa: F. Calouste Gulbenkian/ Fundação para a Ciência e Tecnologia, 2005.

BARROS, C. D. Descrição e classificação dos predicados nominais com o verbo-suporte fazer em Português do Brasil. Tese (Doutorado em Linguística) - Faculdade de Letras, Universidade Federal de São Carlos, São Carlos-SP, 2014. Disponível em: <http://www. bdtd.ufscar.br/htdocs/tedeSimplificado/tde_busca/ arquivo. php?codArquivo=7213>. Acesso em 06/04/2015.

BRUCKSCHEN, M. et al. Anotação linguística em XML do corpus PLN-BR. Série de relatórios do NILC, Núcleo Interinstitucional de linguística Computacional - ICMC/USP, 2008.

GIRY-SCHNEIDER, J. Les nominalisations en français: l'opérateur faire dans le lexique. Genève: Librairie Droz, 1978.

Les prédicats nominaux en français: les phrases simples à verbes support. Genève: Librairie Droz, 1987.

GROSS, G. Un cas des constructions inverses: donner et recevoir. Lingvisticae Investigationes, 2 (1), 1982, pp.1-44. 
Les constructions converses du français. Genève: Librairie Droz, 1989.

GROSS, M. Méthodes en syntaxe. Paris: Hermann, 1975.

Les bases empiriques de la notion de prédicat sémantique. In: Langages, 15e année, n63, 1981. pp. 7-52. doi : 10.3406/lgge.1981.1875. Disponível em: <http://www.persee.fr/ web/revues/home/ prescript/article/lgge_0458-726X_1981_ num_15_63_1875>. Acesso em 06/04/2015.

. La foction sémantique des verbes supports. Travaux de Linguistique, 37, 1998.

MAMEDE, N. et al. STRING: An hybrid statistical and rule-based Natural Language Processing chain for Portuguese. In: Proceedings of PROPOR'12. International Conference on Computational Processing of Portuguese (Demo session), Coimbra, Portugal, April, 2012.

MEUNIER, A. Nominalisations d'adjectifs par verbes supports. Tese (Thèse de Troisième cycle) - Laboratoire Automatique Documentaire et Linguistique, Université Paris 7, 1981.

PAUMIER, S. De la reconnaissance de formes linguistiques à l'analyse syntaxique. Tese (Thèse de Doctorat). Univ. Paris-Est, Marne-la-Vallée, 2003.

MOKHTAR, S. A.; CHANOD, J. P.; ROUX, C. Robustness beyond shalowness: incremental dependency parsing. Natural Language Engineering, 2002, pp.121-144.

RANCHHOD, E. M. Sintaxe dos predicados nominais com Estar. Lisboa: INIC - Instituto Nacional de Investigação Científica, 1990. RASSI, A. P. et al. The fuzzy boundaries of operator verb and support verb constructions with dar "give" and ter "have" in Brazilian Portuguese. In: Proceedings of Workshop on Lexical and Grammatical Resources for Language Processing. Dublin, Ireland, August. Association for Computational Linguistics and Dublin City University, 2014, pp. 92-101.

RASSI, A. P et al. Estudo contrastivo sobre as construções conversas em PB e PE. In: Anais do I Congresso Internacional dos Estudos do Léxico e suas interfaces, Araraquara, SP: UNESP, 2015 (no prelo). 
SANTOS-TURATI, M. C. A. Descrição da estrutura argumental dos predicados nominais com o verbo-suporte ter. In: Seminário do GEL - Grupo de Estudos Linguísticos do Estado de São Paulo, 60, São Paulo, Brasil, 2012, pp. 20-21.

SUÍSSAS, G. Verb Sense Disambiguation. Tese (Tese de Mestrado). Instituto Superior Técnico/ INESC-ID Lisboa - Spoken Language Laboratory, Universidade de Lisboa, 2014.

VIVÈS, R. Avoir, prendre, perdre: Constructions à verbe support et extensions aspectuelles. Tese (Thèse de Troisième cycle), Laboratoire Automatique Documentaire et Linguistique, Université Paris 8, 1983.

\section{Abstract \\ An annotated corpus with support verb constructions in Portuguese}

The support verb constructions (SVC) are a type of nominal construction, where the core predicate is the noun, called 'predicative noun' (Npred), which is assisted by a verb, called 'support verb' (Vsup). The Lexicon-Grammar theoretical and methodological framework was adopted, in this paper, for the linguistic description and formalization of SVC in Portuguese. Considering the syntactic and semantic differences between SVC and other types of constructions, the purpose of this paper is to present the methodology and results of creating a corpus annotated with Vsup and Npred. A list with 4,668 SVC was built, considering 45 variants of Vsup and around 3,200 different Npred. Based on this list, we extracted 121,198 sentences from PLN.Br full corpus, from which 2,646 sentences have been manually annotated. This sample may constitute a reference corpus for the processing of SVC and used as a golden standard for evaluating the automatic tasks of identification, extraction or classification of SVC, as well as for other Natural Language Processing (NLP) applications.

Keywords: support verb, predicative noun. Lexicon Grammar, corpus annotation. 